\title{
Treatment of recent onset central retinal vein occlusion with intravitreal tissue plasminogen activator: a pilot study
}

Agnès Glacet-Bernard, Dagmar Kuhn, Andrew K Vine, Hassiba Oubraham, Gabriel Coscas, Gisèle Soubrane

\begin{abstract}
Aims-To study the effects of intravitreal tissue plasminogen activator (tPA) in recent onset central retinal vein occlusion (CRVO).

Methods-15 patients with recent onset CRVO (from 1-21 days' duration, mean 8 days) were given 75-100 $\mu \mathrm{g}$ of tPA intravitreally associate with low dose low molecular weight heparin. CRVO was perfused in nine patients and with mild ischaemia not exceeding 100 disc diameters in six patients. Follow up ranged from 5 to 21 months for 14 patients (mean 8 months). Visual acuity measurement, macular threshold (Humphrey perimeter), fluorescein angiography with the scanning laser ophthalmoscope with special emphasis on retinal circulation times, and retinal perfusion were performed at days 0,1 , and 8 and months 1,3 , and 6 .
\end{abstract}

Results-Visual acuity was significantly improved on the first day after treatment in only one eye, and decreased transiently in six eyes $(40 \%)$. Retinal blood velocity was not significantly modified by tPA injection. Retinal ischaemia developed in six eyes (43\%), leading to panretinal photocoagulation in five eyes including one with rubeosis iridis. At the end of follow up, visual acuity had improved to $20 / 30$ or better in five eyes $(36 \%)$, including two with complete recovery; visual acuity was worse than $20 / 200$ in three eyes $(28 \%)$. No complication of tPA injection was observed.

Conclusion-Intravitreal tPA treatment for CRVO appears to be simple and safe, but did not significantly modify the course of the occlusion in our patients immediately after treatment. Final visual outcome did not differ significantly from that observed in the natural course of the disease, but final visual acuity seemed to be slightly better. A randomised study is required to determine if intravitreal tPA actually improves visual outcome in CRVO.

(Br f Ophthalmol 2000;84:609-613)

Correspondence to: Agnès Glacet-Bernard, MD, University Eye Clinic of

Créteil, 40, avenue de

Verdun, 94000 Créteil,

France

agnes.glacet@chicreteil.fr

Accepted for publication 28 January 2000 poor. ${ }^{1-6}$ Recently, many contributory factors have been found in the pathogenesis of retinal vein occlusion, such as raised blood viscosity and abnormalities in various haemostatic factors-for example, increased factor VIII, deficiencies of protein $\mathrm{C}, \mathrm{S}$, and antithrombin III , activated protein $C$ resistance, etc. These abnormalities of haemostasis may result in a hypercoagulable state and thrombus formation, leading to the occurrence of retinal vein occlusion, or to the development of retinal ischaemia and iris neovascularisation..$^{711} \mathrm{~A}$ thrombus has also been observed in each case of central retinal vein occlusion (CRVO) in histopathological studies. ${ }^{12}$ These findings suggest that outflow obstruction is due to thrombosis and that fibrinolytic agents could be an appropriate treatment for retinal vein occlusion. However, thrombus formation as the primary event is always questioned, and the pathogenesis of retinal vein occlusion remains unclear.

Systemic administration of fibrinolytic agents had been performed in small series of CRVO patients. ${ }^{13-17}$ This treatment showed beneficial effects on retinal blood flow in some cases, but was associated with the risk of massive vitreous haemorrhage and severe systemic complications (cerebral haemorrhage) leading to the termination of some of these studies. Systemic administration of fibrinolytic agents is therefore not recommended in retinal vein occlusion.

Intravitreal administration of fibrinolytic agents, which avoids systemic complications of fibrinolytic therapy, has been evaluated in a pilot study (Lahey et al, presented at the AAO Annual Meeting, Chicago, 1996). This pilot study was designed to evaluate the effects of intravitreal injection of low doses of tissue plasminogen activator (tPA) combined with low molecular weight heparin on ocular status and particularly on retinal blood flow, and its influence on the course of CRVO.

\section{Patients and methods}

Fifteen patients were recruited between January 1997 and April 1998 for the study. The major inclusion criteria were the presence of CRVO of recent onset (less than 3 weeks) and a decrease in visual acuity (20/40 or less). CRVO was defined as the presence of retinal haemorrhages in all four quadrants. Diagnosis was always confirmed by fluorescein retinal angiography.

Excluded from the study were patients with late onset CRVO (duration of symptoms of more than 3 weeks); patients with only a slight decrease in visual acuity; patients with CRVO 
already complicated with anterior or posterior neovascularisation or already treated by laser photocoagulation; patients with other ocular disorders known to decrease visual acuity (such as uncontrolled glaucoma, cataract, age related macular degeneration, and diabetic retinopathy); pregnant women and children.

The nature of the study was explained to each patient, who were asked to give informed consent, according to the Helsinki-Tokyo declaration. The study protocol was approved by the ethics committee (Comite Consultatif de Protection des Personnes dans la Recherche Biomédicale) of the Henri Mondor hospital.

A complete ophthalmological examination was performed just before the intravitreal injection (day 0 ), and at days 1,8 , and 15, and months 1, 3, and 6. Examination included ocular and medical history, visual acuity measurement with ETDRS chart, macular threshold testing with the Humphrey perimeter (Carl Zeiss, Le Pecq, France), biomicroscopy, applanation tonometry, fundus examination, and fluorescein angiography with the scanning laser ophthalmoscope (SLO, Rodenstock), with special emphasis on retinal circulation times and retinal capillary bed evaluation. The retinal transit time was defined as the difference between the laminar venous flow and the arterial flow in the major retinal vessels. Ischaemic areas were measured in disc diameters on central and peripheral fields. Improvement or deterioration in visual acuity was documented as two or more lines of difference on the logarithmic visual acuity chart. Improvement in macular threshold corresponded to an increase of two decibels in the measure- ment with the Humphrey perimeter. Retinal transit time was considered as improved or deteriorated if it varied by 2 seconds or more.

Intravitreal tPA administration was performed under topical anaesthesia and after local disinfection. tPA (Actilyse, Boehringer Ingelheim, France) was injected into the vitreous cavity with a 30 gauge needle through the pars plana. The dose of tPA was $100 \mu \mathrm{g}$ in 0.1 $\mathrm{ml}$ for the first five patients; the dose was then diminished to $75 \mu \mathrm{g}$ in $0.075 \mathrm{ml}$ for the 10 next patients, after the report of the possibility of retinal pigment changes, as described by Ruiz LaPuente et al with a $30 \mu \mathrm{g}$ injection (presented at the AAO annual meeting, San Francisco, 1997). A small anterior chamber paracentesis was often performed before the tPA injection to prevent an increase in intraocular pressure. Low dose subcutaneous low molecular weight heparin (2500 IU per day) was started at the day of tPA treatment and continued for 7 days in order to prevent rethrombosis.

\section{Results}

Pertinent data of the 15 patients included in this study are summarised in Table 1 . The ages of the patients ranged from 37 to 74 years (mean 61.5 years); there were $10(67 \%)$ men and five $(33 \%)$ women. Hypertension was present in six $(40 \%)$ patients, hyperlipidaemia in six $(40 \%)$, open angle glaucoma in three $(20 \%)$, diabetes without retinopathy in one $(7 \%)$, cardiovascular history in four $(27 \%)$, positive smoking history in eight $(53 \%$, six had stopped smoking, two of them recently, the other four for more than 10 years). Laboratory

Table 1 Clinical course of CRVO after intravitreal TPA injection, classified from the shorter to the longer duration of symptoms before treatment

\begin{tabular}{|c|c|c|c|c|c|c|c|c|}
\hline $\begin{array}{l}\text { Case } \\
\text { no }\end{array}$ & $\begin{array}{l}\text { Age } \\
\text { (years) }\end{array}$ & $\operatorname{Sex}$ & Associated medical conditions & $\begin{array}{l}\text { CRVO duration } \\
\text { before TPA } \\
\text { injection (days) }\end{array}$ & $\begin{array}{l}\text { Dose of } \\
\text { TPA }\end{array}$ & $\begin{array}{l}\text { Initial visual } \\
\text { acuity }\end{array}$ & Initial form of CRVO & Visual outcome \\
\hline 1 & 64 & M & $\begin{array}{l}\text { Hypertension, smoking, } \\
\text { activated protein C resistance, } \\
\text { CRVO in the second eye }\end{array}$ & 1 & $75 \mu \mathrm{g}$ & $20 / 70$ & $\begin{array}{l}\text { non-ischaemic } \\
\text { CRVO }\end{array}$ & 20/20, non-ischaemic CRVO \\
\hline 2 & 60 & $\mathrm{~F}$ & $\begin{array}{l}\text { Hypercholesterolaemia, } \\
\text { glaucoma, HRT }\end{array}$ & 2 & $100 \mu \mathrm{g}$ & $20 / 40$ & $\begin{array}{l}\text { non-ischaemic } \\
\text { CRVO }\end{array}$ & $\mathrm{CF}$, ischaemic CRVO, PRP \\
\hline 3 & 70 & M & Hyperlipidaemia & 4 & $75 \mu \mathrm{g}$ & $20 / 30$ & $\begin{array}{l}\text { peripheral ischaemic } \\
\text { area of } 30 \mathrm{DD}\end{array}$ & $\begin{array}{l}\text { 20/200, CME, unchanged ischaemic } \\
\text { area }\end{array}$ \\
\hline 4 & 69 & $\mathrm{~F}$ & None & 5 & $100 \mu \mathrm{g}$ & $20 / 400$ & $\begin{array}{l}\text { non-ischaemic } \\
\text { CRVO with } \\
\text { cilioretinal AO }\end{array}$ & $\begin{array}{l}\mathrm{CF} \text {, ischaemic CRVO, PRP, } \\
\text { preretinal neovascularisation }\end{array}$ \\
\hline 5 & 58 & M & Glaucoma & 5 & $100 \mu \mathrm{g}$ & $20 / 200$ & $\begin{array}{l}\text { non-ischaemic } \\
\text { CRVO with } \\
\text { cilioretinal AO }\end{array}$ & 20/125, non-ischaemic CRVO, CME \\
\hline 6 & 57 & M & Diabetes, stopped smoking & 5 & $75 \mu \mathrm{g}$ & $20 / 40$ & $\begin{array}{l}\text { non-ischaemic } \\
\text { CRVO }\end{array}$ & 20/400, ischaemic CRVO, PRP \\
\hline 7 & 53 & M & $\begin{array}{l}\text { Myocardial infarction, } \\
\text { hyperlipidaemia, stopped } \\
\text { smoking }\end{array}$ & 5 & $75 \mu \mathrm{g}$ & $20 / 30$ & $\begin{array}{l}\text { non-ischaemic } \\
\text { CRVO }\end{array}$ & 20/70, non-ischaemic CRVO, CME \\
\hline 8 & 74 & M & Stopped smoking & 5 & $100 \mu \mathrm{g}$ & $20 / 70$ & $\begin{array}{l}\text { non-ischaemic } \\
\text { CRVO }\end{array}$ & \\
\hline 9 & 37 & $\mathrm{~F}$ & Smoking & 6 & $75 \mu \mathrm{g}$ & $20 / 40$ & $\begin{array}{l}\text { non-ischaemic } \\
\text { CRVO }\end{array}$ & 20/15, non-ischaemic CRVO \\
\hline 10 & 72 & $\mathrm{~F}$ & $\begin{array}{l}\text { Hypertension, overweight, } \\
\text { hypercholesterolaemia, }\end{array}$ & 8 & $75 \mu \mathrm{g}$ & $20 / 40$ & $\begin{array}{l}\text { non-ischaemic } \\
\text { CRVO }\end{array}$ & 20/25, non-ischaemic CRVO \\
\hline 11 & 72 & $\mathrm{~F}$ & Hypertension, overweight & 8 & $100 \mu \mathrm{g}$ & $\mathrm{CF}$ & ischaemic CRVO & $\mathrm{CF}$, ischaemic CRVO, PRP \\
\hline 12 & 49 & $\mathrm{M}$ & $\begin{array}{l}\text { Hyperlipidaemia, overweight, } \\
\text { stopped smoking }\end{array}$ & 14 & $75 \mu \mathrm{g}$ & $20 / 50$ & $\begin{array}{l}\text { peripheral ischaemic } \\
\text { area of } 30 \mathrm{DD}\end{array}$ & $\begin{array}{l}\text { 20/40, unchanged ischaemic area, } \\
\mathrm{CME}\end{array}$ \\
\hline 13 & 61 & $M$ & $\begin{array}{l}\text { Hypertension, myocardial } \\
\text { infarction, stopped smoking }\end{array}$ & 15 & $75 \mu \mathrm{g}$ & $20 / 160$ & $\begin{array}{l}\text { non-ischaemic } \\
\text { CRVO }\end{array}$ & 20/25, non-ischaemic CRVO \\
\hline 14 & 67 & $M$ & $\begin{array}{l}\text { Hypertension, glaucoma, } \\
\text { myocardial infarction }\end{array}$ & 21 & $75 \mu \mathrm{g}$ & $20 / 400$ & $\begin{array}{l}\text { peripheral ischaemic } \\
\text { area of } 20 \mathrm{DD}\end{array}$ & $\begin{array}{l}\text { CF, ischaemic CRVO, rubeosis iridis, } \\
\text { PRP }\end{array}$ \\
\hline 15 & 60 & $M$ & $\begin{array}{l}\text { hypertension, } \\
\text { hyperlipidaemia, angina } \\
\text { pectoris, stopped smoking }\end{array}$ & 21 & $75 \mu \mathrm{g}$ & $20 / 50$ & $\begin{array}{l}\text { non-ischaemic } \\
\text { CRVO }\end{array}$ & 20/20; non-ischaemic CRVO \\
\hline
\end{tabular}

PRP = panretinal photocoagulation; HRT = hormone replacement therapy for postmenopausal woman; $\mathrm{DD}=$ disc diameters; $\mathrm{CMO}=$ cystoid macular oedema; $\mathrm{AO}$ $=$ artery occlusion; $\mathrm{CF}=$ counting fingers. 


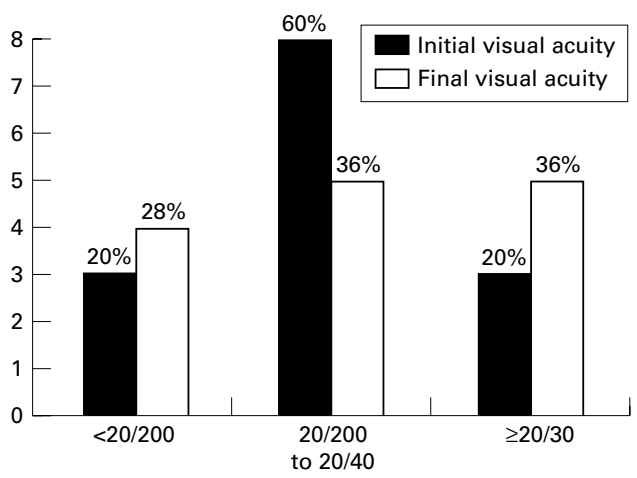

Figure 1 Distribution of initial and final visual acuity in patients treated by intravitreal tPA injection.

investigation disclosed protein $\mathrm{C}$ resistance in one hypertensive 64 year old man. Only one patient (a 69 years old woman) was free of any vascular risk factor.

Diagnosis and treatment of CRVO was performed on the first day of the occlusion in one patient, on the second day in another patient, between day 4 and day 6 in seven patients, on day 8 in two patients, on day 14 in two patients, and on day 21 in two patients. The mean time between the onset of CRVO and treatment was 8 days.

Before treatment, three $(20 \%)$ eyes had visual acuity of $20 / 30$ or better, nine $(60 \%)$ had visual acuity ranging from $20 / 200$ and $20 / 30$, and three (20\%) eyes had less than 20/200 (Fig $1)$. On fluorescein angiography, CRVO was well perfused in nine $(60 \%)$ eyes; two other eyes had a good perfusion of peripheral retinal but displayed small ischaemic areas (2 and 5 disc diameters) at the posterior pole corresponding to a combined occlusion of a cilioretinal artery. Peripheral ischaemic area was present in four $(27 \%)$ eyes at the first visit (20-30 disc diameters in three eyes, and 100 disc diameters in one eye).

tPA injection was accomplished according to the protocol without complication. Ophthalmological examination was performed according to the protocol schedule except for one patient who failed to return for follow up after the day 1 visit. Mean follow up was 8 months (5-21 months) for the others.

At day 1 after tPA injection, visual acuity dramatically improved in one patient (the one treated on the first day of a perfused CRVO), while it was unchanged in eight eyes (53\%) and worsened in six eyes (40\%, Fig 2). One week after injection, visual acuity had improved in three eyes $(22 \%)$, was unchanged in nine eyes $(64 \%)$, and had worsened in two eyes $(14 \%)$. At the end of follow up, visual acuity was improved in five eyes (36\%), unchanged in five eyes $(36 \%)$, and worsened in four eyes $(28 \%)$. At the end of follow up, five (36\%) eyes had visual acuity of $20 / 30$ or better, five $(36 \%)$ had visual acuity ranging from $20 / 200$ to $20 / 30$, and four (28\%) eyes had less than 20/200 (Fig 1). Variations of macular threshold (Humphrey perimeter) were grossly similar to those of visual acuity, as shown in Figure 3.

Fluorescein angiography with the SLO showed a moderate but significant slow down in retinal circulation times (of $2-3$ seconds) in six eyes $(50 \%)$ immediately after injection, and no change in six other eyes; no improvement in retinal circulation times was observed at day 1 . At the end of follow up, an improvement in retinal circulation times was observed in five eyes $(38 \%)$, a slow down in one eye, and no change in seven eyes (54\%).

A slight increase in retinal haemorrhages was observed in six cases. New haemorrhages occurred in previous ischaemic areas in four eyes, and in two well perfused eyes. They were often perivascular, transient, and without complications.

The CRVO remained perfused in six eyes $(43 \%)$ and converted into an ischaemic form in two eyes $(14 \%)$. Four eyes (28\%) with initially mild or moderate ischaemia had an extension of ischaemic areas. Therefore retinal ischaemia was present at the end of follow up in eight eyes $(57 \%)$, including six cases $(43 \%)$ in which it appeared or extended, and two cases with no change. Rubeosis iridis occurred in one eye, preretinal neovascularisation in one other eye. Panretinal photocoagulation was performed in five eyes and limited peripheral photocoagulation in one eye.

Posterior vitreous detachment probably occurred after treatment in four eyes between days 1 and 7 . Posterior vitreous detachment was difficult to ascertain by ocular examination in many cases and data about vitreous status were often questionable.

No complications were observed (no retinal detachment, vitreous haemorrhage, or endophthalmitis) as a result of either the tPA injection

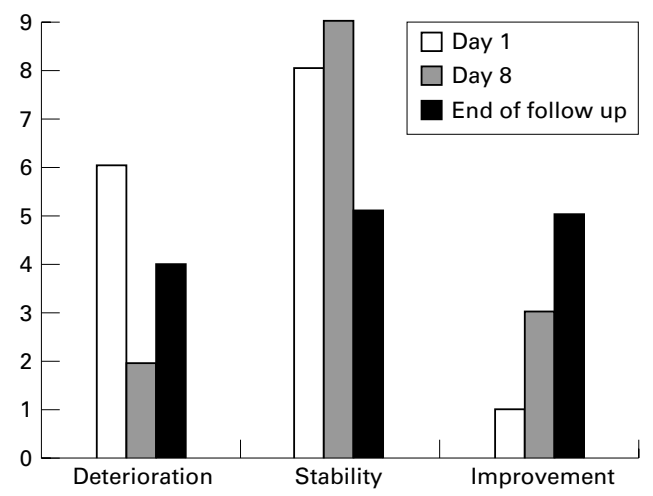

Figure 2 Changes in visual acuity immediately, at 1 week, and at the end of follow up, after tPA injection.

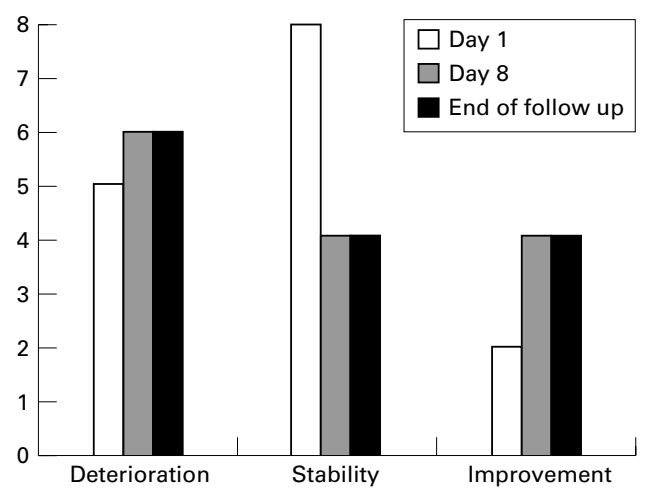

Figure 3 Changes in macular threshold after tPA injection. 
or the subcutaneous low molecular weight heparin administration.

No correlation was found between visual acuity improvement and tPA doses (75 or 100 $\mu \mathrm{g})$, or the time of the injection.

\section{Discussion}

Recombinant human tissue type plasminogen activator (tPA) is a relatively clot selective fibrinolytic agent with a molecular weight 70000 Da. Advantages of tPA over the non-selective fibrinolytic agents (such as streptokinase or urokinase) are its superior results in achieving reperfusion (demonstrated in myocardial infarction ${ }^{18}$ ), higher efficacy in the lysis of older thrombi, its lack of antigenicity, and its enhanced fibrin selectivity, which leads to greater therapeutic activity. tPA was first successfully administered in ocular surgery to dissolve traumatic hyphaema or postcataract fibrinous membranes. ${ }^{19}$ Particularly striking was the rapidity of the fibrinolysis with disappearance of all products of fibrin dissolution within 4 hours. Results in treatment of postvitrectomy fibrin formation are controversial. ${ }^{20-22}$ tPA has been found effective in subretinal haemorrhages related to macular degeneration, either by the intravitreal or subretinal route. ${ }^{23-25}$ Intravitreal tPA was first tried in CRVO by Lahey et al to attempt to dissolve intravenous thrombi and to avoid systemic complications of intravenous administration of fibrinolytic agents.

In this study, 15 CRVO eyes treated with intravitreal injection of tPA were followed for a mean period of 8 months and underwent ophthalmological examination and fluorescein angiography with the SLO at each visit. Results on the first day and on the first week after the injection are disappointing because, based on previous studies on fibrin dissolution, we had expected a rapid effect on retinal outflow obstruction. A dramatic improvement in visual acuity was observed in only one case immediately after treatment. On the contrary, $40 \%$ of the eyes experienced an initial decrease in visual acuity and a slow down in retinal circulation times on fluorescein angiography, but the majority of them returned to their initial level in an 8 day period. One week after treatment, about the fifth of eyes showed an improvement in visual acuity and in retinal circulation times. tPA did not seem then to influence retinal circulation times and visual acuity within the first days of the injection. The transient decrease in visual acuity and retinal circulation times might be explained by a mild inflammatory reaction induced by the injection, but no inflammatory signs, media opacities, or increase in intraocular pressure were observed after treatment.

Our results seem similar to those previously reported by Lahey, using a similar protocol of treatment (intravitreal injection of $65-110 \mu \mathrm{g}$ of tPA), who described an improvement in visual acuity to $20 / 40$ or better in $33 \%$ of the patients followed for 6 months. Thus, tPA injection seems to favourably influence long term visual outcome, but does not improve early signs of CRVO, which was expected in our study.

No correlation was observed between visual outcome and the time of the treatment (Table 1 ), except for the patient treated on the day of the occurrence of the CRVO, a 64 year old hypertensive man with activated protein C resistance, who had experienced CRVO in the fellow eye 7 years earlier, with poor visual outcome (final visual acuity of $20 / 200$ ). Improvement in visual acuity observed on the first day persisted with longer follow up, with total recovery at the final visit: final visual acuity was $20 / 20$ in the treated eye. This suggests that tPA injection may be effective within the first hours of the CRVO, or that this treatment is effective only in patients with abnormalities of haemostasis leading to thrombus formation; in the majority of cases with normal haemostasis, the main contributory factor to CRVO is probably hyperviscosity which may not be influenced by fibrinolytic agents.

These findings may explain why intravitreal injection seems less effective than haemodilution therapy, which leads to a dramatic decrease in blood viscosity and rapidly improves retinal circulation times, with long term efficacy on visual acuity. ${ }^{26-28}$

Good results have also been reported in a pilot study using intra-arterial fibrinolysis in CRVO. $^{29}$ Urokinase (30 $\left.000 \mathrm{IU}\right)$, delivered into the ophthalmic artery by transfemoral catheterisation, gave a dramatic improvement in visual acuity in $38 \%$ of cases, especially when CRVO was associated with delayed arterial retinal filling on fluorescein angiography. These cases of combined central retinal artery and central retinal vein occlusion represent probably a different entity which seems to respond more successfully to fibrinolytic therapy than standard CRVO. Intra-arterial injection would allow fibrinolytic agents to reach the site of the occlusion more efficiently than intravitreal injection. However, the diffusion of tPA though the vitreous gel and its passage through the venous wall remain to be elucidated. The occurrence of posterior vitreous detachment in some of our patients tends to demonstrate that tPA is effective in the vitreous cavity during some hours or days. Lewis recently showed that tPA does not diffuse through the neural retina to reach the subretinal space in the rabbit, but the passage through the venous wall and the presence of tPA at the lamina cribrosa have not yet been analysed.

In this study, no complications occurred after intravitreal injection of tPA, which appeared to be easy and safe. We did not observe retinal pigment changes after injection, as described by Ruiz LaPuente et al. This treatment is also free of contraindications, in contrast with haemodilution or intra-arterial fibrinolysis. However, a randomised trial is needed to establish if intravitreal injection of tPA actually improves visual outcome in CRVO.

The authors have no proprietary interest in any of the materials used in this study. 
1 The Central Vein Occlusion Study Group. Baseline and early natural history report. The Central Vein Occlusion Study. Arc

2 The Central Vein Occlusion Study Group. Natural history and clinical management of central retinal vein occlusion Arch Ophthalmol 1997;115:486-91.

3 Coscas G, Dhermy P. Occlusions veineuses rétiniennes. Paris: Masson, 1978:283-346.

4 Quinlan PM, Elman MJ, Bhatt AK, et al. The natural course of central retinal vein occlusion. Am $\mathcal{f}$ Ophthalmol 1990;110:118-23.

5 Glacet-Bernard A, Coscas G, Chabanel A, et al. Prognostic factors for retinal vein occlusion. A prospective study of 175 cases. Ophthalmology 1996;103:551-60.

6 Chen JC, Klein ML, Watzke RC, et al. Natural course of perfused central retinal occlusion. Can f Ophthalmol 1995 30:21-4.

7 Vine AK, Samama MM. The role of abnormalities in the anticoagulant and fibrinolytic systems in retinal vascular anticoagulant and fibrinolytic systems in reting

8 Williamson TH, Rumley A, Lowe GDO. Blood viscosity, coagulation, and activated protein $\mathrm{C}$ resistance in central coagulation, and activated protein $\mathrm{C}$ resistance in central
retinal vein occlusion: a population controlled study. $\mathrm{Br}$ retinal vein occlusion: a popul

9 Glacet-Bernard A, Chabanel A, Lelong F, et al. Elevated erythrocyte aggregation in patients with central retinal vein occlusion and without conventional risk factors. Ophthalmology 1994;101:1483-7.

10 Ring CP, Pearson TC, Sanders MD, et al. Viscosity and retinal vein thrombosis. Br $\mathcal{F}$ Ophthalmol 1976;60:397-410.

11 Trope GH, Lowe GDO, Mc Ardle BM, et al. Abnormal blood viscosity and haemostasis in long-standing retinal vein occlusion. Brf Ophthalmol 1983;67:137-42.

12 Green WR. Histopathologic studies of hypotensive retinopathy, branch vein occlusion, and central retinal vein occlusion. In: Fine SL, Owens SL eds. Management of retinal vascular and macular disorders. Baltimore: Williams and Wilkins, 1983:5-27.

13 Coscas G, Soubrane G. Occlusion de la veine centrale de la rétine: anticoagulants et fibrinolytiques (urokinase). Prerétine: anticoagulants et fibrinolytiques (urokinase). Pre

14 Kohner EM, Laatikainen L, Oughton J. The management of central retinal vein occlusion. Ophthalmology 1983:90:484-7.

15 Kreutzer A, Brunner R, Schaefer H, et al. Treatment of central retinal vein occulsion with rt-PA. Fortschr Ophthalmo 1988;85:511-3.

16 Steinkamp GW, Hattenbach LO, Scharrer I, et al. Front-loading-rt-PA-Lysetherapie bei Zentral- oder Vene- nastverschlussen des Nezthaut. Ophthalmologe 1994;91: $280-2$

17 Elman MJ, Quinlan P, Fine SL, et al. Thrombolytic therapy for central retinal vein occlusion. Invest Ophthlalmol Vis Sci 1988,29(suppl):68.

18 Williams DF, Borer J, Braunwald E, et al. Intravenous recombinant tissue-type plasminogen activator in patients with acute myocardial infarction: a report from the NHLBI thrombolysis in myocardial infarction trial. Circulation 1986;73:338-46.

19 Moon J, Chung S, Myong Y, et al. Treatment of postcataract fibrinous membranes with tissue plasminogen activator. Ophthalmology 1992;99:1256-9.

20 Jonhson RN, Olsen KR, Hernandez E. Intravitreal tissue plasminogen activator treatment of experimental vitreous hemorrhage. Arch Ophthalmol 1989,107:891-4.

21 Koutsandrea C, Apostolopoulos M, Theodossiasdis P. The use of tissue plasminogen activator in postvitrectimy cases. Int Ophthalmol 1993;17:95-100.

22 Jaffe GJ, Abrams GW, Williams GA, et al. Tissue plasminogen activator for postvitrectomy fibrin formation. Ophthalmology 1990;97:184-9.

23 Lewis $\mathrm{H}$. Intraoperative fibrinolysis of submacular hemorrhage with tissue plasminogen activator and surgical drainage. Am f Ophthalmol 1994;118:559-68.

24 Benner JD, Hay A, Landers MB, et al. Fibrinolytic-assisted removal of experimental subretinal hemorrhage within seven days reduces outer retinal degeneration. Ophthalmology 1994;101:672-81.

25 Ibanez HE, Williams DF, Thomas MA, et al. Surgical management of subretinal haemorrhage, a series of 47 consecutive cases. Arch Ophthalmol 1995;113:62-9.

26 Hansen LL, Wiek J, WiederholT M. A randomised prospective study of treatment of non-ischaemic central retinal vein occlusion by isovolaemic haemodilution. $\mathrm{Br} \mathcal{F}$ Ophthalmol 1989;73:895-9.

27 Wolf S, Arend O, Bertram B, et al. Hemodilution therapy in central retinal vein occlusion. One-year results of a prospective randomized study. Graefes Arch Clin Exp Ophthalmol 1994;232:33-9.

28 Glacet-Bernard A, Coscas G, Cotton A, et al. Study with the SLO of retinal transit times after treatment by isovolemic hemodilution in patients with central retinal vein occlusion. Ophtalmologie 1995;9:194-6.

29 Santiago PY, Paques M, Massin P, et al. Local intra-arterial fibrinolysis for central retinal vein occlusion. Invest Ophthalmo Vis Sci 1996,37(suppl ARVO):S965. 